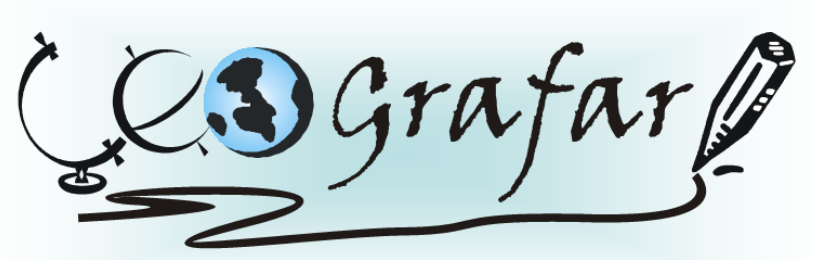

Revista Eletrônica do Programa de Pós-Graduação em Geografia - UFPR

\title{
INJUSTIÇAS AMBIENTAIS NA CIDADE DE SOBRAL/CE: UMA ANÁLISE DA DISTRIBUIÇÃO DE RENDA E DAS ÁREAS DE RISCOS
}

\author{
ENVIRONMENTAL INJUSTICE IN SOBRAL CITY: \\ AN ANALYSIS OF INCOME DISTRIBUTION AND RISK AREAS
}

\author{
Henrique Ricardo Souza Ziegler \\ Doutorando em Desenvolvimento e Meio Ambiente \\ Universidade Federal do Ceará \\ Fortaleza, CE, Brasil \\ e-mail: henriquezie@gmail.com \\ Ana Kércia Sousa Mariano \\ Especialização em Desenvolvimento com Meio Ambiente \\ Universidade Estadual Vale do Acaraú \\ e-mail:kercia_mariano@hotmail.com \\ Silvia Juliane Ventura \\ Doutoranda em Desenvolvimento com Meio Ambiente \\ Universidade Federal do Ceará \\ Fortaleza, CE, Brasil \\ e-mail:sventuraa@gmail.com
}

\begin{abstract}
RESUMO
A finalidade deste artigo é refletir sobre as injustiças ambientais na cidade média de Sobral/CE. O objetivo principal foi propor um mapeamento das injustiças ambientais no município, a partir da análise de duas problemáticas: distribuição da renda na cidade e os riscos ambientais (áreas de alagamento e linhas de transmissão). Primeiramente, realizamos uma discussão sobre os fatores que favoreceram a concentração populacional na cidade, a desconcentração industrial em 1970, a emergência das cidades médias na década de 1990, bem como, sua importância econômica e social. Em seguida, elaboramos uma breve introdução sobre as finalidades da justiça ambiental, em especial, no Brasil, depois fizemos um paralelo entre o desenvolvimento urbano e suas contradições socioambientais na cidade. Entrando no contexto de Sobral, apontamos os principais problemas relacionados ao acesso da população pobre aos bens e serviços públicos e a sua fixação em áreas de risco de alagamento e próximas as linhas de transmissão. Realizamos um registro fotográfico e a localização das áreas de riscos. E por último, discutimos e
\end{abstract}


constatamos as contradições socioambientais encontradas no espaço urbano de Sobral, ou seja, a população de baixa renda, na sua maioria, localiza-se em áreas de riscos, estando mais vulnerável aos riscos ambientais da cidade.

Palavras-chave: Justiça ambiental; Vulnerabilidade Socioambiental; Cidade de médio porte; Alagamento, Linhas de transmissão.

\begin{abstract}
The purpose of this article is to reflect on the environmental injustices in the mediumsized city of Sobral, in the State of Ceará. The main objective was to propose a mapping of environmental injustice in the city, from the analysis of two issues: income distribution in the city and environmental risks (areas of flooding and transmission lines). First, we conducted a discussion of the factors that favored the concentration of population in the cities, industrial decentralization in 1970, the emergence of medium-sized cities in the 1990s, as well as its economic and social importance. Then, we make a brief discussion about the environmental justice, in particular in Brazil, then made a parallel between urban development and its environmental contradictions. Entering the context of Sobral, we point out the main problems related to the access of the poor to public goods and services and its attachment in areas of risk of flooding and near transmission lines. We conducted a photographic record and the location of the risk areas. Finally, we discuss and found the environmental contradictions found in the urban space of Sobral, that is the lowincome population, mostly located in risk areas, being more vulnerable to environmental hazards of the city.
\end{abstract}

Keywords: Environmental justice; Social and environmental vulnerability; Mediumsized city; Flooding; Transmission lines.

\title{
INTRODUÇÃO
}

A discussão sobre injustiça ambiental não está limitada apenas à associação entre os riscos ambientais e suas vítimas. O estudo das causas da alocação desigual desses riscos é de extrema importância para o desenvolvimento de soluções para essa problemática. A distribuição desproporcional dos riscos ambientais é evidente, constatando-se a maior manifestação de riscos sobre as populações negras e com menos recursos financeiros. Dessa forma, renda e etnia são os aspectos centrais para a definição da distribuição dos riscos ambientais. Percebe-se, a partir disso, o estreitamento entre a questão social e a questão ambiental.

Partindo desse pressuposto, surgem alguns questionamentos, como: Toda população da cidade tem acesso aos bens e serviços públicos? Possui uma moradia 
digna e segura? Por que a população pobre vive segregada e em áreas de risco? Há um planejamento urbano que distribua de forma mais justa a população no espaço urbano? Qual a relação entre espaço urbano e justiça ambiental? E as injustiças ambientais estão presentes na cidade?

A partir dessas indagações, podemos refletir que os problemas ambientais e sociais são verificados com mais intensidade nas grandes cidades do Brasil, no entanto, a partir da década de 1990, também se expande em direção às cidades médias. A população pobre dessas cidades desloca-se para a periferia, sofre com a ausência de condições dignas de moradia, encontrando, em muitas situações, uma única alternativa: ocupar irregularmente áreas de riscos. Tais áreas são associadas à vulnerabilidade da população às condições ambientais, posto que, em geral, são localizadas em margens de rios e lagoas, encostas de morros, próximas as linhas de transmissão de alta tensão, dunas, dentre outras.

Considerando-se a relação indissociável entre as problemáticas ambientais e sociais, esse artigo tem como objetivo principal propor o mapeamento das injustiças ambientais no município de Sobral - Ceará, considerando a distribuição de renda e das áreas de risco: linhas de transmissão de alta tensão e áreas propícias a alagamentos. Após o mapeamento é realizada uma discussão com objetivo de expor o panorama das contradições socioambientais na cidade.

Destarte, para o desenvolvimento de nossa pesquisa, inicialmente foi realizado um levantamento bibliográfico acerca da urbanização brasileira atrelada ao processo de desconcentração industrial para a emergência das cidades médias. No segundo momento, discutimos brevemente sobre as bases teóricas do movimento por justiça ambiental e sua relevância na atualidade, diante da intensidade de problemas socioambientais relacionados à questão urbana.

\section{Flexões Sobre o Espaço Urbano Brasileiro}

Após a Revolução Industrial, a cidade surge na perspectiva que a conhecemos hoje, apresentando características da sociedade capitalista. Nela emergem novos espaços de fixos e fluxos, com desdobramento na relação contraditória entre valor de uso e valor de troca e a indissociabilidade entre essas duas dimensões das mercadorias (SPOSITO, 2008). 
Assim, com a "consolidação da sociedade dita capitalista", o espaço da cidade traduz um conjunto de diferenças, na maioria das vezes, conflituosas, tornando-se lócus da pluralidade e das simultaneidades de modelos, de maneiras de viver a vida urbana. A cidade é o espaço dos conflitos, onde a opressão subordina não apenas a classe operária, bem como outras classes sociais (LEFÉBVRE, 1991; SOUZA, 2009a).

No Brasil, a cidade passa por significativas mudanças a partir dos anos de 1970, momento em que a população das cidades ultrapassa o número de habitantes do campo, tal alteração foi motivada por tais motivos: expansão do meio de produção capitalista; intenso desequilíbrio social e regional; avanço da industrialização, concentração de terras; dentre outros fatores. A partir desse período, muitos são os geógrafos brasileiros que se preocupam com as questões urbanas, sobretudo nas grandes metrópoles e, em anos recentes, em cidades de diferentes escalas.

A análise da cidade, do ponto de vista teórico, deve considerá-la em sua função, origem e o processo histórico no qual está inserida, sendo uma orientação basilar para a vida cotidiana da maioria das pessoas. De acordo com Castellar e Vilhena (2011, p. 123):

\footnotetext{
"Ter a cidade como objeto de estudo geográfico é estudar seus sistemas de entradas e saídas; suas vias de acesso em vários pontos; as inter-relações com as aglomerações populacionais; a dinâmica econômica e cultural de seus moradores - que gera as características particulares dos bairros -; as relações socioambientais que se estabelecem; os serviços públicos e os problemas causados pela ausência deles; o quadro da saúde pública; em suma, os diversos elementos que compõem a paisagem do lugar".
}

Para corroborar com a temática, Callai et al. (2007, p.93) relatam que todo esse "movimento mostra que na cidade estão materializadas, por um lado, a dinâmica do capital e, por outro, a dinâmica da sociedade; ambas se expressam contraditoriamente na prática cotidiana dos cidadãos". Nesse sentido,

O grande desafio da sustentabilidade urbana reside na capacidade de tratar as cidades e o seu meio natural em sua especificidade e em toda a sua complexidade, através de uma abordagem multidimensional e interdisciplinar que permita a superação dos desequilíbrios resultantes dessas trocas desiguais, sejam elas internas ou externas à cidade (MELAZO, 2005, p.15). 
No entanto, na realidade o espaço urbano capitalista se apresenta de forma fragmentada, combinada, desigual, reflexo e condicionante social - é um fruto social, resultado de ações acumuladas através do tempo, e concebidas por agentes que produzem e exaurem o espaço. Observa-se na realidade, um intenso jogo de interesses entre os agentes produtores do espaço urbano, e a resistência dos grupos sociais excluídos. Segundo Souza (2000, p.136),

[...] as estratégias de sobrevivência dos pobres urbanos, que podem ser causas imediatas de impactos ambientais negativos, são, elas próprias, condicionadas por determinantes estruturais decorrentes das "lógicas" do modelo social capitalista.

Ao desconsiderar essas desigualdades sociais presentes na cidade, cairemos em manifestações preconceituosas da realidade de boa parcela da população brasileira que sobrevive a condições precárias de moradia, saúde e educação, bem como, condições insatisfatórias de saneamento ambiental e vulnerabilidade a fenômenos ambientais. Segundo Santos (2009, p. 10):

"A cidade em si, como relação social e como materialidade, torna-se criadora de pobreza, tanto pelo modelo socioeconômico de que é o suporte como por sua estrutura física, que faz dos habitantes das periferia pessoas ainda mais pobres. A pobreza não é apenas o fato do modelo socioeconômico vigente, mas, também, do modelo espacial".

Podemos refletir sobre a justaposição de dois graves problemas: pobreza e riscos ambientais. Observa-se na maioria das cidades brasileiras uma dissociação entre planejamento urbano e planejamento ambiental, reforçando a separação entre sociedade e natureza. Com isso, presenciam-se as diferenças sociais vinculadas às moradias em áreas íngremes, em vales, áreas alagadiças etc.

Diante do exposto, tomando como realidade as cidades brasileiras, em especial as cidades médias do nordeste, é necessário retratarmos os interesses dos setores econômicos nessa direção para entendermos o rápido crescimento urbano, o deslocamento da população da metrópole/ cidades médias, e consequentemente, os problemas socioambientais desse crescimento desordenado.

Embora constituindo uma das características da urbanização, a excessiva concentração de pessoas nas grandes cidades, principalmente nas metrópoles, é necessário revelar que centros urbanos dos mais diversos tamanhos, em especial as 
cidades médias, conheceram incremento de suas populações, como pode ser conferido na seguinte argumentação de Steinberger e Bruna (2001, p. 37):

\begin{abstract}
"Em 1970, 28,2\% da população viviam em [cidades] de até 20 mil habitantes, mas em 1980 esta proporção se modificou passando a demonstrar uma tendência de concentração da população em centros de médio porte. [...] várias capitais estaduais tornaram-se metrópoles regionais, comandadas por cidades médias cujos núcleos atingiram entre 500 mil e 1 milhão de habitantes. Ao mesmo tempo, outras cidades médias, com núcleos entre 50 mil e 500 mil habitantes, transformaram-se em centros microrregionais [...]. Desse modo, as cidades médias passaram a desempenhar novos papéis na rede urbana, crescendo em ritmo mais acelerado que as metrópoles".
\end{abstract}

De acordo com Souza (2009b, p. 73), o crescimento populacional das cidades aludidas se deve, dentre outros fatores, "a políticas de ordenamento territorial que visavam 'desafogar' as metrópoles, que eram áreas de forte atração para movimentos migratórios devido à centralização de poder político-econômico". Assim sendo, as cidades médias emergem como uma forma de refrear o fluxo migratório em direção às metrópoles.

Na concepção de Souza (2009b), era necessário investir no desenvolvimento das cidades médias, porque tais centros representavam uma alternativa para melhor equilibrar o sistema urbano nacional.

$\mathrm{Na}$ tentativa de alcançar este equilíbrio, Steinberger e Bruna (2001, p. 44) menciona que foram sugeridas pelo II Plano Nacional de Desenvolvimento (19751979) as seguintes estratégias regionais:

"[...] a desconcentração intra-regional na região Sudeste, a ordenação do sistema urbano da região Sul, a dinamização da base econômica das metrópoles regionais do Nordeste e a promoção da urbanização das áreas de ocupação recente das regiões Norte e Centro-Oeste".

Nesse contexto, as cidades médias apareciam como essenciais, como pode ser observado no detalhamento adiante. No Sudeste do país a prioridade era impulsionar a descentralização de atividades de São Paulo e do Rio de Janeiro para cidades periféricas de porte médio. Além disso, recomendou-se uma desconcentração intrarregional com participação dos centros urbanos superiores a 50 mil habitantes. No Nordeste, o foco principal era a melhoria de infraestrutura das capitais e dos polos secundários regionais, bem como a dinamização de centros 
urbanos regionais para que desempenhassem o papel de polarizador regional (STEINBERGE; BRUNA, 2001).

Em suma, podemos mencionar que a partir dos anos de 1970 as cidades médias passaram a apresentar uma maior importância na rede urbana brasileira, atraindo investidores e atividades que, outrora, dirigia-se exclusivamente para as metrópoles. Além disso, começaram a atrair, mais fortemente, fluxos migratórios procedentes de cidades do seu entorno e de espaços mais distantes. Em razão da desconcentração industrial da região Centro-Sul, a partir da década de 1970, à interiorização do capital industrial e de outros setores econômicos nacionais encaminharam-se em direção às cidades médias, inicialmente da região Sudeste, e em 1990, disseminaram em direção as cidades médias nordestinas.

Além disso, as cidades médias apresentam algumas vantagens perante as metrópoles, pois apresentam menores índices de criminalidade, menor tempo no deslocamento ao trabalho, menores níveis de poluição, aluguéis mais acessíveis, infraestrutura básica educacional e informacional aos seus moradores, mão-de-obra barata e abundante, e incentivos fiscais das prefeituras e do governo estadual. Contrapondo esses aspectos, Carvalho (2002) aponta uma outra perspectiva com a ascensão das cidades médias:

"[...] a urbanização impôs um ritmo mais lento ao crescimento das metrópoles, incrementando as taxas de crescimento das cidades médias. Não se distribuiu riqueza mas, sim, pessoas, por todo território nacional. Os encargos municipais, para suprir as novas demandas, certamente tornarão a vida, nessas cidades, mais cara, particularmente no que diz respeito aos bens e serviços públicos".

Dessa forma, essas cidades de médio porte passam a apresentar, em menor escala, problemas sociais e ambientais, até então, presentes apenas nas grandes cidades. A segregação sócio-espacial verificada com mais veemência nas grandes cidades, também se expande em direção às cidades médias. A população pobre dessas cidades desloca-se para a periferia, muitas vezes, para áreas desprovidas de serviços básicos, de infra-estrutura e equipamento urbanos. Sofre também com a ausência de condições dignas de moradia, encontrando, em muitas situações, uma única alternativa: ocupar irregularmente áreas insalubres. Tais áreas são associadas à vulnerabilidade da população às condições ambientais, posto que, em geral, são localizadas em margens de rios e lagoas, encostas de morros, próximas as linhas de transmissão de alta tensão, dunas, dentre outras. 


\section{Justiça Ambiental No Brasil}

Os movimentos sociais norte-americanos deram origem à expressão justiça ambiental, quando na década de 1960, começaram a reivindicar direitos civis às populações afrodescendentes existentes nos Estados Unidos da América (EUA), nesse período, passaram a protestar contra a exposição humana à contaminação tóxica de origem industrial.

Segundo Acselrad (2004), foi a partir das lutas de base similares que a justiça ambiental constituiu uma problemática central nas lutas do movimento por direitos civis nos EUA. Nesse contexto, ressaltamos o lançamento do estudo "Rejeitos tóxicos e raça nos EUA" em 1987, que demonstrou que os depósitos de resíduos perigosos nos EUA estavam localizados principalmente próximo à comunidades afrodescendentes. A partir desse momento criou-se a expressão "racismo ambiental" para designar "a imposição desproporcional - intencional ou não - de rejeitos perigosos às comunidades de cor" (ACSELRAD, 2004, p. 26).

A partir da década de 1990, houve uma forte difusão do movimento por justiça ambiental, ultrapassando os limites territoriais norte-americanos, fez com que novas perspectivas fossem consideradas ao movimento e ganhassem espaço nas conferências mundiais. Seguindo o mesmo raciocínio, Rammê (2012, p.27) complementa:

\footnotetext{
"Evidencia-se, portanto, que a dimensão global alcançada pelo movimento por justiça ambiental introduziu uma nova crítica ao debate ambiental, direcionada ao processo de produção capitalista. No atual modelo neoliberal de desenvolvimento, há uma lógica econômica perversa, que ignora por completo a ideia de equidade na repartição das externalidades negativas do processo produtivo".
}

A questão da injustiça ambiental não se limita à simples interação entre os riscos ambientais e suas vítimas. Realizar o diagnóstico das causas da distribuição desigual desses riscos é de extrema importância para o desenvolvimento de soluções para esse problema. Só será possível alcançar a justiça ambiental se as causas da problemática forem identificadas, explicadas e, então, efetivamente resolvidas. Para tanto, é imprescindível a articulação entre a sociedade, o governo e as grandes corporações do mercado, além de cooperação a nível mundial. Pois, para Moreira (2015, p.2) é perceptível uma alocação desproporcional dos riscos ambientais 
[...] verificando-se a maior incidência de riscos sobre as populações negras e com menos recursos econômicos. Dessa forma, renda e raça são os principais critérios para a definição da distribuição dos riscos ambientais. Percebe-se, a partir disso, a interrelação entre a questão social e a questão ambiental. Ambas andam de mãos dadas, não sendo possível resolver uma delas sem tutelar também a outra.

Recentemente, o movimento por justiça ambiental passou a envolver todos os conflitos socioambientais, cujos riscos sejam suportados de forma proporcional sobre populações socialmente vulneráveis ou mesmo sobre os países em desenvolvimento e pobres. Por ausência de rigidez no cumprimento da legislação ambiental e da justiça social, grande parte dos países da América Latina, Ásia e África apresentam graves injustiças ambientais.

Nota-se o agravamento desses riscos ambientais no último século, devido a uma forte desconcentração da produção industrial das grandes corporações internacionais para os países em desenvolvimento, na busca por fatores atrativos, tais como: isenção fiscal, recursos naturais, mão-de-obra barata e abundante, expansão do mercado consumidor, e principalmente, precária fiscalização trabalhista e ambiental. Favorecendo, dessa forma, as estratégias da expansão do capitalismo e das injustiças ambientais.

No Brasil, as injustiças sociais encobrem e naturalizam um conjunto de situações caracterizadas pela desigual distribuição de poder sobre a base material da vida social e do desenvolvimento. A injustiça e a discriminação, portanto, aparecem na apropriação elitista do território e dos recursos naturais, na concentração dos benefícios usufruídos do meio ambiente e na exposição desigual da população à poluição e aos custos ambientais do desenvolvimento (ACSELRAD; HERCULANO; PÁDUA, 2004, p. 10).

Na década de 1990, já havíamos presenciado movimentos sociais em defesa do meio ambiente. Mas foi a partir de 2001, contudo, fruto do encontro de organizações não-governamentais, sindicatos de trabalhadores, ambientalistas, movimentos indígena e negros e pesquisadores universitários no I Colóquio Internacional sobre Justiça Ambiental, Trabalho e Cidadania, realizado no campus da Universidade Federal Fluminense em Niterói, foi criada a Rede Brasileira da Justiça Ambiental (RBJA). Segundo essa rede, justiça ambiental se define por: 


\begin{abstract}
O conjunto de princípios e práticas que:
a - asseguram que nenhum grupo social, seja ele étnico, racial ou de classe, suporte uma parcela desproporcional das consequências ambientais negativas de operações econômicas, de decisões de políticas e de programas federais, estaduais, locais, assim como da ausência ou omissão de tais políticas;

b - asseguram acesso justo e eqüitativo, direto e indireto, aos recursos ambientais do país;

c - asseguram amplo acesso às informações relevantes sobre o uso dos recursos ambientais e a destinação de rejeitos e localização de fontes de riscos ambientais, bem como processos democráticos e participativos na definição de políticas, planos, programas e projetos que lhes dizem respeito; $\mathrm{d}$ - favorecem a constituição de sujeitos coletivos de direitos, movimentos sociais e organizações populares para serem protagonistas na construção de modelos alternativos de desenvolvimento, que assegurem a democratização do acesso aos recursos ambientais e a sustentabilidade do seu uso (REDE BRASILEIRA DE JUSTIÇA AMBIENTAL, 2001).
\end{abstract}

De acordo com a rede, a justiça ambiental está alicerçada em quatro noções básicas, que podem ser considerados: 1) distribuição igualitária das consequências ambientais negativas decorrentes das atividades humanas; 2) equidade no acesso aos recursos naturais; 3) democracia participativa e direito à informação; 4) sustentabilidade. Levando em conta esse pilares, busca-se a igualdade social e a sustentabilidade ambiental, por meio de movimentos da justiça ambiental.

Diante disso, a noção de justiça ambiental revela um movimento de ressignificação da problemática ambiental, ocorrida por meio de estratégias dos movimentos sociais envolvidos nas lutas ambientais. Conquistando mudanças na escala estatal e na legislação pela proteção ambiental e social.

Porém as injustiças ambientais continuam se intensificando nas cidades brasileiras, destacamos as cidades médias, como recorte espacial, pois se apresentam como estratégia do sistema capitalista, ao se tornarem refúgios da produção industrial (fatores atrativos locacionais) em massa, expansão de atividades comerciais e da sociedade do consumo. Caso contrário, Acselrad (2010, p.213) ressalta que:

"[...] se as empresas não obtiverem as vantagens fiscais, terreno de graça, flexibilização de normas ambientais, urbanísticas e sociais, também se "deslocalizam", penalizando, consequentemente, os estados e municípios onde é maior o empenho em preservar conquistas sociais e ambientais".

É nesse contexto adverso que as cidades médias passam também a concentrar as desigualdades socioambientais. Nesse sentido, a cidade de Sobral se depara com as contradições socioambientais, tais como: expansão da segregação 
sócio-espacial em áreas de riscos (alagamentos, linhas de transmissão, indústrias químicas, declividade, dentre outros); instalação de empreendimentos portadores de risco (indústrias poluentes, lixões), além da falta de infraestrutura básica (saneamento, abastecimento de água e energia, transporte e vias de circulação). Tais vulnerabilidades devem ser considerados ao analisarmos a problemática socioambiental enfrentada pela população, especialmente pelas comunidades periféricas e/ou de baixa renda.

\section{METODOLOGIA}

A pesquisa centraliza-se na cidade de Sobral, (figura 1), especificamente em sua área urbana consolidada, situada no noroeste do estado do Ceará, a $235 \mathrm{~km}$ de Fortaleza, capital do estado. Sobral possui uma área total de 2.122,98 Km2, altitude máxima de 69,49 metros acima do nível do mar, estando inserida na depressão sertaneja, cujo bioma predominante é a caatinga e população média de 201.756 habitantes, sendo considerada uma população de médio porte (IBGE, 2010).

O clima é considerado tropical quente semiárido e tropical quente semiárido brando, com temperaturas médias variando entre $26^{\circ} \mathrm{C}$ e $28^{\circ} \mathrm{C}$, tendo seu período chuvoso entre os meses de janeiro a maio com pluviosidade média de $821,6 \mathrm{~mm}$ (IPECE, 2014).

Quanto aos aspectos socioeconômicos do município, apresenta um IDH médio alto de 0,714 e uma população predominantemente urbana, com a taxa de urbanização de 88,3\%. Apesar da relevância das atividades industriais, o setor de comércio e serviços sobressai na cidade com 68,14\% do PIB, em 2011 (IPECE, 2014).

No que diz respeito aos procedimentos metodológicos, propomos um mapeamento das injustiças ambientais no município de Sobral, considerando a distribuição de renda e das áreas de risco: linhas de transmissão de alta tensão e áreas propícias a alagamentos. Para tal, foram utilizadas as bases informacionais do IBGE, para distribuição de renda familiar por bairro; e da Prefeitura de Sobral, através da Secretaria de Urbanismo, para localização dos bairros, grade de logradouros e das áreas de risco. 


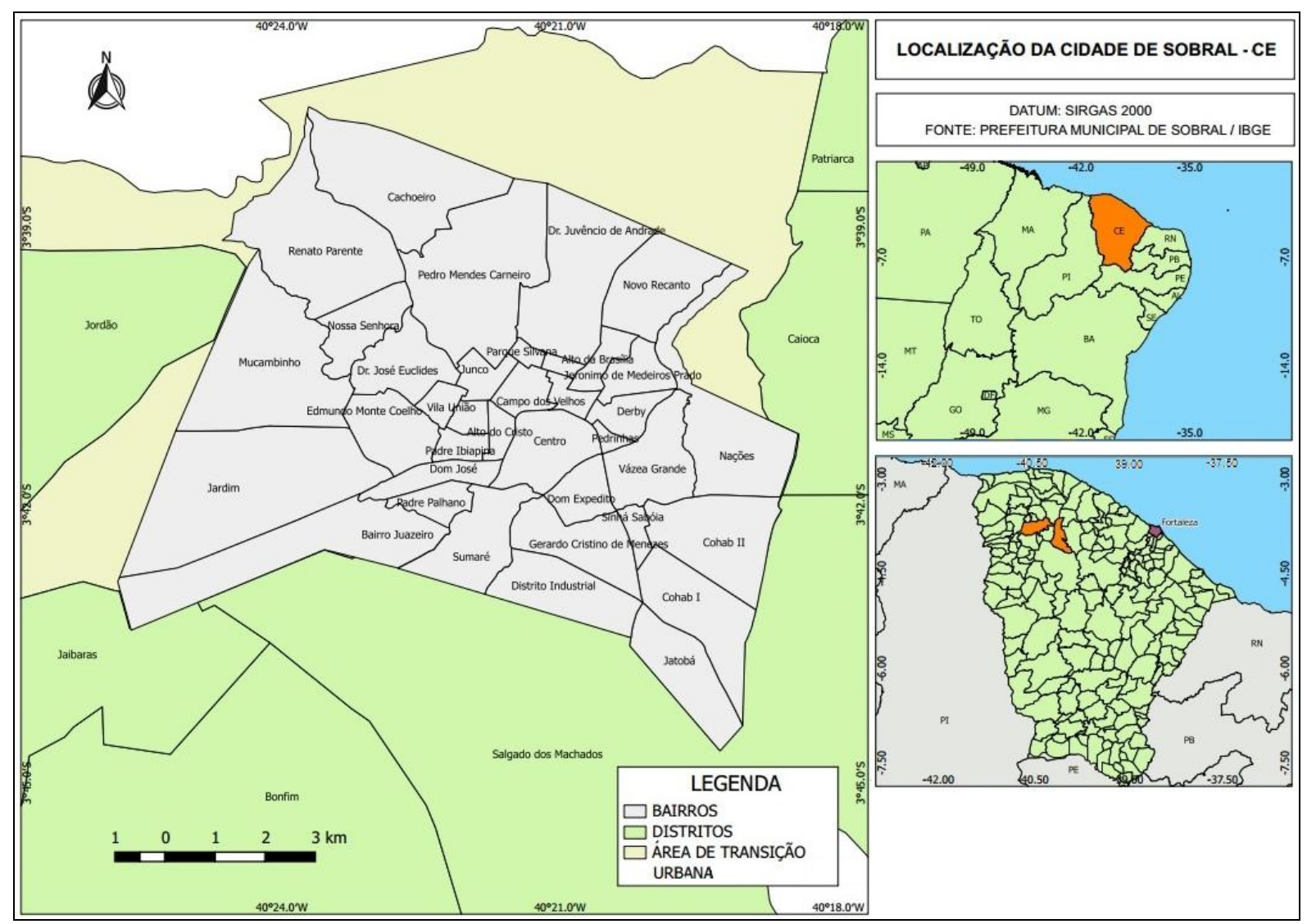

Figura 1 - Mapa de Localização da Cidade de Sobral - Ceará.

Trata-se de uma pesquisa de cunho exploratório, com abordagem qualitativa, com o objetivo de caracterizar o problema e buscar sua compreensão por meio de dados estatísticos e registros fotográficos.

\section{As Contradições Socioambientais na Cidade de Sobral}

Atualmente as cidades médias apresentam problemas relacionados ao uso e ocupação do solo, à discordância entre os ritmos do crescimento da população e da expansão urbanística; ao saneamento ambiental, à alteração dos cursos d'água e sua contaminação; mudanças no ciclo vital da flora e da fauna urbana; o crescente número de veículos privados e seus efeitos no tráfego e a poluição atmosférica; ao déficit habitacional e de serviços. E, sobretudo, o quadro muitas vezes alarmante de segregação e desigualdade social, que se manifesta também na forma de violência urbana. Todos estes aspectos refletem fortemente sobre a qualidade de vida nas cidades. Catuzzo (2002, p. 17) complementa, apontando as peculiaridades da urbanização brasileira quanto aos problemas urbanos: 
"[...] acrescenta que os principais problemas urbanos são de ordem social e econômica, sendo a pobreza (de ordem social) a tendência que tem favorecido o agravamento de problemas urbanos tais como especulação imobiliária (responsável pelo crescimento desordenado), falta de infraestrutura, ineficiência dos sistemas gestores e agressões ao meio ambiente".

Diante do exposto, Sobral possui um espaço urbano articulado economicamente e ao mesmo tempo, contraditório no que diz respeito aos problemas sociais e ambientais. Percebemos o processo de naturalização das injustiças ambientais com população pobre que reside em morros, próximos de linhas de transmissão de energia elétrica, áreas alagadiças, lixo, indústrias poluidoras e áreas desprovidas de serviços públicos (hospitais, creches, escolas, segurança, fiscalização ambiental, etc.) onde existe grande necessidade de planejamento. O planejamento democrático é uma boa alternativa a esses problemas, ele deve buscar a formação de um conjunto de ativistas entre funcionários públicos, profissionais, políticos, empresários e lideranças sociais. É importante estabelecer espaços de negociação considerando os diferentes conflitos existentes, evitando as desigualdades de acesso às informações e poder (MARICATO, 2010)

Dentre tantas injustiças ambientais existentes, destacaremos duas: primeiro moradias localizadas próximas as linhas de transmissão de energia e, segundo, as áreas propícias a alagamentos. Localizadas, principalmente em bairros populosos, tais como: Terrenos Novos, Dom Expedito, Cohab 1, Sinhá Saboia e Sumaré (figura 2).

As contradições ocorrem devido ao baixo poder aquisitivo da população, a forte especulação imobiliária, valorização de alguns bairros em detrimento de outros, moradias precárias nos bairros mais populosos, baixo nível educacional, crescimento da criminalidade, e em áreas de riscos, percebe-se assim o modelo de urbanização excludente, que priva as comunidades de baixa renda das mais básicas condições de urbanidade. Conforme observa Rolnik (2011), essa exclusão ou segregação delineada no espaço da cidade coloca, de um lado, uma minoria privilegiada instalada em parcela central do território, isto é, contemplada com todos os padrões urbanísticos legais e assistida pelo poder público em infraestrutura; e do outro, parte da população que se vê obrigada a buscar regiões periféricas, 
promovendo uma ocupação desordenada e marcada por processos de invasões ou remoções, ilegalidade e carências de infraestrutura e investimentos públicos.

Podemos observar no mapa (figura 2) de localização das áreas de riscos de Sobral, que a concentração dessas vulnerabilidades firmam-se, principalmente, em bairros com menor renda familiar, como Terrenos Novos, Sumaré, Dom Expedito, Cohab I, Sinhá Saboia, Alto da Brasília e Expectativa. Essas localidades são as mais populosas da cidade, além da área central. Verificamos que há uma relação indissociável entre o baixo nível socioeconômico dos bairros e os problemas ambientais, ou seja, há várias ameaças naturais na cidade, mas a sua intensidade ocorre em bairros mais vulneráveis, onde a população pobre não possui a condição de decidir onde residir. Dessa forma, ocupam áreas de vales, de margens de rios (Figura 3), próximas à linha de alta tensão (Figura 4), lixões, indústrias químicas, dentre outras.

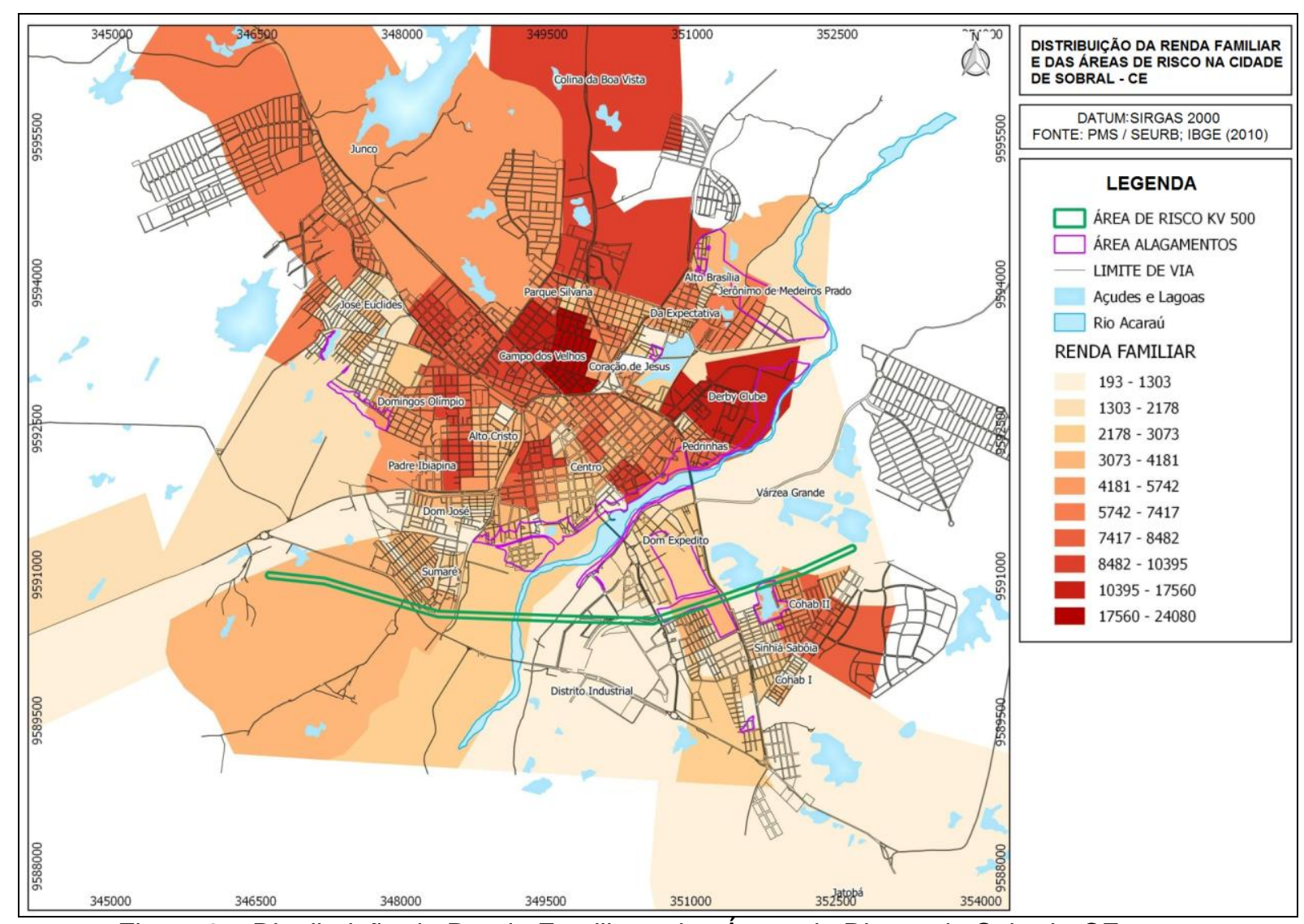

Figura 2 - Distribuição da Renda Familiar e das Áreas de Riscos de Sobral - CE 


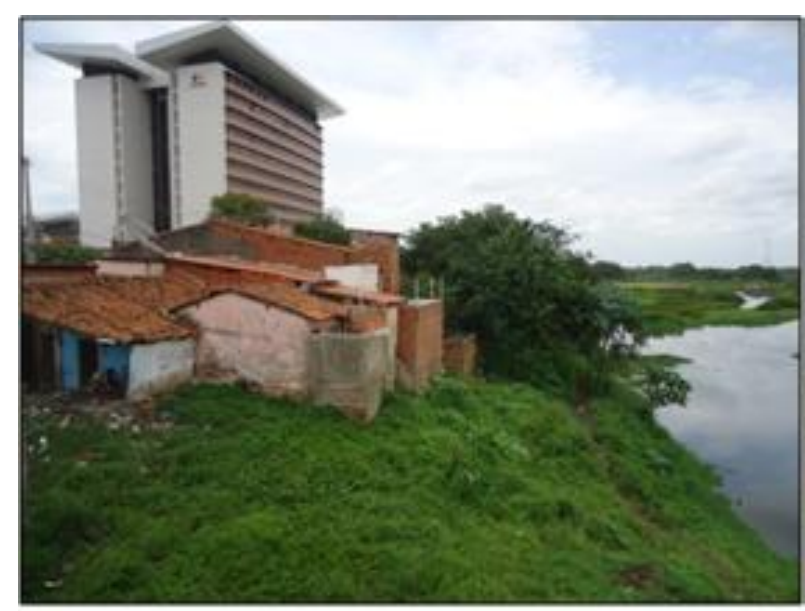

Figura 3 - Área de alagamento no bairro Dom Expedito, Sobral - CE.

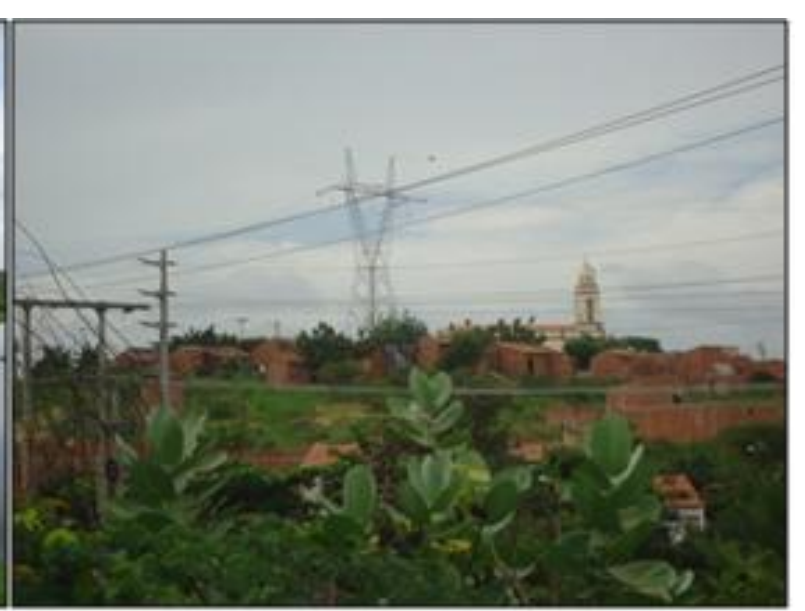

Figura 4 - Residências próximas à linha de transmissão no bairro Sumaré, Sobral - CE.

A imagem retratada (figura 3), demonstra a forte contradição socioeconômica, de um lado o shopping Center e do outro uma comunidade pobre chamada "Gaviões", além de ser uma área de risco alagamento, no bairro Dom Expedito. Na figura 4, ressalta-se o risco de acidentes pela proximidade das casas com as de torres de alta tensão. Em seguida, podemos observar na figura 5, a localização de várias residências, lixo e esgoto no interior de uma lagoa, em que nos períodos de fortes chuvas, ocorrem alagamentos. E por último, figura 6, demonstramos os portes e fios de alta tensão no interior de residências, no bairro dos Terrenos Novos.



Figura 5 - Casas e lixo na lagoa, bairro Terrenos Novos, Sobral - CE.
Figura 6 - Portes e fios de alta tensão no interior, bairro Terrenos Novos, Sobral. 
Segundo Acselrad (2009) citado por Moreira (2015, p. 2) "[...] é possível constatar que sobre os mais pobres e os grupos étnicos desprovidos de poder recai, desproporcionalmente, a maior parte dos riscos ambientais socialmente induzidos". Com isso, notamos que a cidade de Sobral ao apresentar um discurso modernizador, contraditoriamente, também nos mostra as injustiças ambientais em um território estrategicamente desigual e articulado.

Ao realizar a discussão sobre a justiça ambiental em cidades médias brasileiras e expor algumas injustiças ambientais da cidade de Sobral por meio do mapeamento das áreas de riscos ambientais, notamos que algumas áreas dos bairros periféricos citados são as localidades mais atingidas pela disparidade social e ambiental, sendo ao mesmo tempo, as que mais crescem demograficamente como apresentado na Figura 2. De forma proporcional á desigualdades de condições de ocupação do território, aumenta a desigualdade no acesso das oportunidades de crescimento econômico. Isto porque, quando as empresas se instalam tendem a privatizar terras e recursos comuns, militam para a supressão das formas não capitalistas de produção e a expulsão dos camponeses das suas terras (HARVEY, 2014). Para estas transnacionais a terra é fonte de acumulação do capital, negligenciando a cultura local, a história, as tradições, os mitos fundadores, símbolos materiais e imateriais, a sociabilidade existente, as relações de solidariedade que se configuram. Segundo Zhouri (2013), estes e outros elementos são geradores de conflitos ambientais. Apesar dos conflitos e da injustiça social serem notáveis em diferentes territórios onde avançam os projetos de desenvolvimento, a ideologia desenvolvimentista não retrocede.

\section{CONCLUSÃO}

A cidade média de Sobral/CE tem nas atividades terciárias um dos seus principais destaques, o que a torna uma área polarizadora que influencia um vasto território no noroeste do estado cearense. A cidade apresenta tal dinâmica ao receber, diariamente, fluxos de pessoas que buscam satisfazer suas necessidades.

No entanto, essa cidade também apresenta um leque de desigualdades sociais e ambientais, no que diz respeito a segregação socioespacial em áreas de vulnerabilidades ambientais, localizadas geralmente, nos bairros periféricos, onde a 
população possui poucos recursos econômicos e situadas em áreas de riscos, tais como: alagamentos, lixões, margens de rios e lagos, morros e próximas às linhas de alta tensão.

Com isso, a partir da localização das áreas de riscos, selecionamos as duas que consideramos mais relevantes: linhas de transmissão de energia e áreas propícias a alagamentos, devido à extensão territorial atingida, assim como população atingida. Os bairros mais populosos e os de baixa renda (Terrenos Novos, Sumaré, Dom Expedito, Sinhá Saboia, dentre outros) estão mais propícios a sofrer com os riscos, por estarem localizados em áreas vulneráveis a alagamentos, incêndios, choques elétricos e curto circuito. Tais riscos são resultantes das ações dos agentes naturais potencializados pelas atividades humanas.

Dessa forma, percebemos que a condição financeira influencia na exposição às vulnerabilidades sociais (miséria, favelização, fome e marginalização) e ambientais (alagamentos, incêndios, poluição industrial, choque elétrico), atingindo mais diretamente as populações de baixo poder aquisitivo.

Diante disso, acreditamos na necessidade de reconstrução de um Estado soberano e de bem-estar social, que seja resistente as estratégias de interesses econômicos. Sabemos da importância de investimentos em pesquisas e tecnologia, em saneamento básico, saúde, em educação e em outros fatores que são indispensáveis. Mas a distribuição desses benefícios entre a sociedade deve ocorre de forma mais justa e uniforme, com a finalidade de amenizar as disparidades sociais. Só será possível a efetivação da justiça ambiental se a solução da problemática social for também buscada.

As reflexões sobre as injustiças ambientais na de Sobral visou apenas dar suporte para o debate na intenção de que outros estudos sobre a temática venham a ser realizados.

\section{Referências}

ACSELRAD, H. Ambientalização das lutas sociais - o caso do movimento por justiça ambiental. In: Estudos Avançados. v.24, n.68. São Paulo, 2010. 
ACSELRAD, $\mathrm{H}$. As práticas espaciais e o campo dos conflitos ambientais. In: ACSELRAD, H. (org).Conflitos Ambientais no Brasil. Rio de Janeiro: Relume/Dumará: Fundação Heinrich Böll, 2004.

ACSELRAD, H. HERCULANO, S., PÁDUA, J. A. A Justiça Ambiental e a Dinâmica das Lutas Socioambientais no Brasil: uma introdução. In: HERCULANO, Selene; PÁDUA, José Augusto (org.). Justiça Ambiental e Cidadania. Rio de Janeiro: Relume Dumará; Fundação Ford, 2004.

ACSELRAD, H.; MELLO, C. C. do A.; BeZERRA, G. das N. O que é Justiça Ambiental. Rio de Janeiro: Garamond, 2009.

CALLAI, H. C.; CASTELLAR, S. M. V.; CAVALCANTI, L. de S. Lugar e cultura urbana: um estudo comparativo de saberes docentes no Brasil. In: Terra Livre, Presidente Prudente, ano 23, v. 1, n. 28, 2007.

CARVALHO, E. de. Cidades brasileiras, crescimento e desigualdade social. In: Revista ORG \& DEMO. n. 3, São Paulo, 2002.

CASTELLAR, S. V.; VILHENA, J. Ensino de Geografia. São Paulo: Cengage Learning, 2011. (Coleção Ideias em Ação)

CATUZZO, H. Análise da legislação urbanística considerado os princípios diretrizes de sustentabilidade: o caso de Jaboticabal, SP. São Carlos: UFSCAR, 2002.

IBGE - Instituto Brasileiro de Geografia e Estatística. Censo Demográfico 2010: Perfil socioeconômico de Sobral. Disponível em: http://cidades.ibge.gov.br/xtras/perfil.php?codmun=231290. Acesso em abr. de 2016.

IPECE: Perfil básico municipal. Disponível em: http://www.ipece.ce.gov.br/publicacoes/perfil_basico/pbm-2014/Sobral.pdf Acesso em dez de 2015.

LEFÉBVRE, H. O Direito à Cidade. Editora Moraes, 1991.

MARICATO, E. Para entender a crise urbana. Ed. Expressão Popular, São Paulo. 2015.

MELAZO, G. C. A percepção ambiental e educação ambiental: uma reflexão sobre as relações interpessoais e ambientais no espaço urbano. In: Revista Olhares \& Trilhas, Uberlândia, v.6, n. 6, 2005.

MOREIRA, R. B. A Alocação Desproporcional dos Riscos Ambientais e a Construção de Justiça Ambiental. In: Âmbito Jurídico, Rio Grande, XVIII, n. 139, ago $2015 . \quad$ Disponível em: $<$ http://www.ambitojuridico.com.br/site/?n link=revista artigos leitura\&artigo id=162 60․ Acesso em dez 2015. 
RAMMÊ, Rogério Santos. Da justiça ambiental aos direitos e deveres ecológicos: conjecturas políticos-filosóficas para uma nova ordem jurídico. Caxias do Sul, RS: Educs, 2012.

Rede Brasileira de Justiça Ambiental - RBJA. Manifesto de Lançamento da Rede Brasileira de Justiça Ambiental. Disponível em: $<$ http://www.mma.gov.br/destaques/item/8077-manifesto-de-lan\%C3\%A7amento-darede-brasileira-de-justi\%C3\%A7a-ambiental/>. Acesso em ago 2015.

ROLNIK, R., "A construção de uma política fundiária e de planejamento urbano para país- avanços e desafios". In: IPEA políticas sociais - acompanhamento e análise. 2006.

ROLNIK, R.; KLINK, J.. Crescimento econômico e desenvolvimento urbano: por que nossas cidades continuam tão precárias?. Novos estud. - CEBRAP, São Paulo, n. 89, p. 89-109, Mar. 2011.

SANTOS, Milton. A Urbanização Brasileira. 5 ed. São Paulo: Editora da Universidade de São Paulo, 2009.

SOUZA, C. B. G. A contribuição de Henri Lefebvre para reflexão do espaço urbano da Amazônia. Revista Franco-Brasilera de Geografia, n. 5, 2009a.

SOUZA, M. V. M. de. Cidades Médias e Novas Centralidades: Análise dos subcentros e eixos comerciais em Uberlândia (MG). 2009. 236 f. Dissertação (Mestrado em Geografia) - Instituto de Geografia, Universidade Federal de Uberlândia, Uberlândia, 2009b.

SOUZA, M. L. de. O desafio metropolitano: um estudo sobre a problemática sócioespacial nas metrópoles brasileiras. Rio de Janeiro: Bertrand Brasil, 2000.

SPOSITO, E. S. Redes e Cidades. São Paulo: Editora UNESP, 2008.

STEINBERGER, M; BRUNA, G. C. Cidades médias: elos do urbano-regional e do público-privado In: ANDRADE, T e SERRA (orgs). Cidades médias brasileiras. Rio de Janeiro: IPEA, 2001.

ZHOURI, A.; OLIVEIRA, R. Conflitos entre desenvolvimento e meio ambiente no Brasil: desafio para a Antropologia e os antropólogos. In: FIELDMAN-BIANCO, B. (org). Desafios da Antropologia brasileira. Brasília: ABA, 2013. 